\title{
RESGATE DA IDENTIDADE CULTURAL DA CIDADE DE MANAUS: ESTUDO DA IMPORTÂNCIA DE ASPECTOS CULTURAIS PARA PROJETOS DE MOBILIÁRIOS URBANOS
}

\author{
Yago de Jesus Santos Ferreira \\ Universidade Federal do Amazonas \\ yagosantos.ferreira@gmail.com \\ Fabio Henrique Dias Máximo \\ Universidade Federal do Amazonas \\ dias.maximo@gmail.com
}

Resumo: A urbanização das cidades evoluíram ao longo do tempo, transformando as pequenas vilas em grandes centros urbanos. Em Manaus não foi diferente, e devido a desvalorização da cultura local, dificultou-se a criação de espaços urbanos com traços da cultura local. Assim, a pesquisa propõe identificar parâmetros, para aplica-los em projetos de mobiliários urbanos e construir uma nova relação do manauara com o seu meio urbano. Para tanto, trabalhou-se com método adaptado de levantamento de dados e observação, de forma simultânea e ordenada, para o projeto de mobiliários urbanos. Houve um levantamento bibliográfico acerca da cultura regional e suas manifestações, assim como a utilização do espaços públicos pelos habitantes, pode-seobter dados fundamentais para embasamento da pesquisa. Como resultados, percebeu-se a grande negligência dos centros urbanos, ao não levarem em consideração os aspectos simbólicos no projeto de mobiliários urbanos além de ter-se entendido a linha tênue entre forma, função desses elementos. Conclui-se que os resultados alcançados podem, além de serem a chave para basear projetos de intervenção na malha urbana de uma cidade, também fornece parâmetro para outras pesquisas acerca do design nos espaços públicos.

Palavras-chave: Cultura, Design, Intervenção Urbana, Mobiliário Urbano, Manaus. 


\section{INTRODUÇÃO}

O processo de urbanização das cidades se sofisticaram significativamente ao longo dos milênios e são responsáveis pela metamorfosedos primeiros arruamentos que se tornaram nas metrópoles da atualidade. No que diz respeito a Manaus, capital do Amazonas com mais de 340 anos e cerca de 2 Milhões de habitantes, percebe-se uma herança cultural forte da sua fundação, mas que ao mesmo tempo é negada aos habitantes atuais no que diz respeito à malha contemporânea da cidade.

A pesquisa apresenta uma análise dos significados de cultura e sua importância para a construção do ambiente urbano. Entretanto, como pretende ir além da manifestação física da cidade, também mostra conceitos simbólicos do que é o espaço urbano. Para isso é fundamental estudar o imaginário entre o usuário do sistema, seus vínculos, relações e interações com a cultura local e o estado dessa relação. Isso porque os espaços físicos existem com o objetivo de servir os habitantes das redondezas e, portanto, tem obrigação de fazer com que estes indivíduos tenham, além de um ambiente funcional, um local que possam se sentir conectados.

Além de estudar as relações entre homem e cidade, também há a necessidade de apontar aspectos que devem ser levados em consideração durante o projeto de mobiliário urbano em geral; afinal, o mobiliário urbano já não deve mais se preocupar apenas com seu peso funcional e formal, mas também com características culturais que o ambiente carrega, gerando apelo emocional aos seus usuários. Logo, o mobiliário urbano torna-se responsável pela interação entre o homem e a cidade, pois gera impressões, positivas ou não, do ambiente para com o habitante integrando-os em um único sistema.

Ao mesmo tempo que o trabalho questiona o método atual de produção dos mobiliários urbanos, procura resgatar e demonstrar que cada vez mais tem-se deixado para trás a cultura e o apelo emocional nos projetos de ambientes urbanos, pontos que são tão importantes quanto os aspectos formais e funcionais nesse tipo de projeto. Dessa forma, a pesquisa beneficia não só a comunidade acadêmica, mas também civis, residentes da cidade de Manaus, e a própria cidade, ao despertar o interesse por soluções que criem laços mais fortes (de estima) entre cidadão e cidade.

\section{CULTURA: ABORDAGEM REFLEXIVA}

Cultura é uma palavra que traz à tona diversos conceitos. Por ter vários conceitos e ser estudada por muitos, ainda não é possível uma ideia fechada. Assim, seu significado torna-se vasto e apresenta-se de inúmeras formas.

Linguisticamente, de acordo com William (2007) o Latim tem grande importância para grande parte do vocábulo ocidental, e nesta língua usada pelos antigos romanos, a palavra cultura aborda significados bastante fechado, porém diversos. Habitar, cultivar, proteger, honrar são alguns deles.

William (2007) comenta que apesar do contexto linguístico apresentado, historicamente, o conceito de cultura contemporâneo começou a ser formado na França, junto com o lluminismo. Cuche (2002) afirma que é durante o movimento que o significado começa a ser difundido com aspecto mais "abstrato"; Sendo ela (a cultura), tratada como valores humanos passados por geração em geração. 
Segundo Cuche (2002), no mesmo período, o termo também começa a ganhar outros significados em outros lugares do Planeta, como na Alemanha. Diferente dos franceses, os alemães enxergavam a cultura mais como um patrimônio físico, expressado através de obras artísticas. Algo que formasse uma identidade a uma nação.

A grande questão é perceber que este conceito desde sua base no latim, onde era abordado de forma mais concreta, até o século XVIII, esteve sempre em evolução, dependendo das percepções históricas para seguir adiante. Logo pode-se garantir que o significado do termo não teria ganho tais proporções sem seus reflexos mais "primitivos".

Mesmo com tantas possibilidades, foi sintetizada por Edward Burnett Tylor (1832-1917), uma concepção mais "universal" acerca de cultura. O antropólogo apresenta em um sentido etnográfico que cultura é "este todo complexo que inclui conhecimentos, crenças, arte, moral, leis, costumes ou qualquer outra capacidade ou hábitos adquiridos pelo homem como membro de uma sociedade".

Portanto, "devemos ter em mente que cada indivíduo tem bagagem diferenciada e principalmente "culturas" singulares (nem menos, nem mais avançadas e sim mais ou menos complexas)", pois, como explica Batista (2010), suas bases estão fundadas em estruturas anteriores formadas em um processo lento de diversas gerações.

Pode-se dizer então que a cultura caracteriza um povo. Logo aceitar que devido a inúmeros povos, por consequência, existem diferentes tipos de culturas. Devido isso Marconi e Pressotto (2006) afirmam a importância do Relativismo Cultural; que consiste na capacidade de compreender cada cultura dentro do seu contexto e da sua realidade.

Os estudiosos ainda explicam sobre a aculturação, que é o processo de interrelações ou contatos entre grupos e culturas diferentes. No processo de inter-relações, Laraia (2009) explica que todas as pessoas avaliam as outras culturas a partir da sua e sempre consideram a própria cultura superior às demais, evidenciado claros casos de etnocentrismo. Laburthe e Warnier (2003) alertam que muitas vezes o etnocentrismo costuma ser disfarçado por atitudes que são até louvadas, como é o caso do patriotismo. Aliás Marconi e Presotto (2006) explicam que este também pode ser manifestado com comportamento agressivo ou em atitudes de superioridade e até hostilidade. Um contexto histórico que reflete as consequências do etnocentrismo é o próprio Brasil. Marconi e Presotto (2006) afimam quem no ínico do século XX, havia cerca de 230 grupos tribais no País. Em 1957, ainda segundo os estudiosos, eles já haviam sido reduzidos a 143, e em 1977 restavam apenas 116 grupos. E ainda fica claro que o processo aculturativo no Brasil resultou na subordinação e na dizimação de muitas tribos e de milhões de indígenas.

\section{ESPAÇO E MOBILIÁRIO URBANO: PLACEMAKING}

O espaço público pode ter uma identidade, positiva ou negativa, e pode facilitar ou restringir as oportunidades de encontro e compartilhamento de experiências no local onde se vive (LANG, 2006), e analisando isso, podemos entender sua história, e consequentemente sua cultura, pois através da cultura o ser humano é capaz de 
vencer obstáculos, superar situações complicadas e modificar o habitat (LARAIA, 2009).

Para entender melhor o que é um habitat, Correa e Naoumova (2015), afirmam que espaços públicos urbanos se apresentam como uma organização estrutural, não só com características físicas, mas também simbólicas, e estas características determinam o sucesso do habitat. Já Crawford (1999) defende que acomodar as necessidades da vida cotidiana faz o espaço público ser passível de apropriação e transformação pelos usuários, e isto conduz o mesmo espaço integrar-se ao homem e o lugar.

Correa e Naoumova (2015) defendem que a ideia de transformar um lugar, através da cultura, redesenhando-o para atingir de forma mais incisiva a interação "homem e espaço" vem sendo discutida e aplicada no Brasil como um processo de planejamento conhecido como Placemaking. Esse tipo de planejamento visa estimular maiores interações entre as pessoas, e por consequência promover comunidades mais saudáveis e felizes de forma empírica. Para isso, o processo tem o objetivo de transformar os espaços públicos em pontos de encontro, sendo os espaços: ruas, calçadas, parques, edifícios e demais locais públicos. Stamps (1989) confirma o enfoque de Correa e Naoumova (2015) ao utilizar de evidências de seus próprios estudos onde ambientes urbanos cuidadosamente arranjados atraem as pessoas e as fazem sentir-se melhor.

Para entender melhor sobre a interação do homem e a cidade, é preciso entender a história das transformações urbanas. Segundo Choay (2001), a aceleração da urbanização no início do século XX fez com que a cidade deixasse de ser vista como um museu para ser reconhecida como tecido vivo, conciliando sua morfologia com novos usos. Gonzáles-Varaz (2003) explica que a partir da segunda metade do século passado, "passou-se a haver um interesse cada vez maior aos aspectos nos quais se plasma a cultura de um povo". Isto é: línguas, ritos, comportamentos coletivos e até mesmo relações sociais.

Hoje em dia, grande parte da população vive e trabalha em centros urbanos e segundo a perspectiva das Nações Unidas (2007), até 2050, esse número atingirá os 6.4 bilhões de pessoas, ou seja,70\% da população mundial estará concentrada nas cidades. Levando isto em consideração, vale lembrar que segundo Zanirato (2006), o ambiente urbano, enquanto lócus de concentração populacional, é um dos lugares privilegiados de expressão dos suportes materiais e simbólicos produzidos e reproduzidos pelos grupos humanos.

Portanto, no que se diz respeito às cidades, pode-se levar em consideraçãoque ela (a cidade) "tornou-se então um nível específico da prática social, um lugar de expressão da memória coletiva, de identidades compartilhadas pelos diferentes habitantes que a integram", (CHOAY, 2001).

\subsection{Intervenções urbanas}

O desenvolvimento urbano tem implicado na transformação das paisagens urbanas e, consequentemente, das imagens da cidade, que têm se modificado enquanto informações sobre a realidade apreendida pelos usuários (Chou; Andrade, 1996).

Entretanto, Portas (1998) já havia conceituado intervenções urbanas como: "[...] o conjunto de programas e projetos [...] que incidem sobre os tecidos urbanizados dos aglomerados, sejam antigos ou relativamente recentes, tendo em vista: a sua 
reestruturação ou revitalização funcional [...]; a sua recuperação ou reabilitação arquitetônica [...]; finalmente a sua reapropriação social e cultural (...)", (PORTAS, 1998).

Por outro lado, o que determina se um espaço é valorizado como espaço público, não é tanto o seu estatuto de propriedade ou o seu design, mas sim sua utilização e partilha diária por diferentes indivíduos e grupos; que caracterizam este ambiente (ÁGUAS, 2012).

\section{MOBILIÁRIO URBANO}

Tendo em vista esse cenário, Pizzato, Guimarães e Tonetto (2014), apontam que as investigações recentes que unem a Ergonomia e o Design à emoção devam ser também direcionadas a produtos de uso coletivo, como o mobiliário urbano que por definição são artefatos direcionados à comodidade e ao conforto dos usuários e, em especial, aos pedestres (MONTENEGRO, 2005).

Já Kohlsdorf (1996), trata o mobiliário urbano como integrante dos elementos complementares do espaço urbano, ao afirmar que esses elementos muitas vezes são "os principais responsáveis pela imagem dos lugares" (KOHLSDORF, 1996). Freitas (2008) compara elementos ou mobiliários urbanos ao mobiliário doméstico, quando enfatiza que "o mobiliário urbano contribui para a estética e para a funcionalidade dos espaços, da mesma forma que promove a segurança e o conforto dos usuários". (FREITAS, 2008).

Entretanto, Filho (2004) defende que o mobiliário urbano tem apresentado desvio de sua função utilitária, agregando valores estéticos e/ou escultóricos, compondo conjuntos decorativos em praças e em parques públicos. De qualquer modo, ambos os elementos (mobiliário urbano e arte urbana) buscam validar a identidade do lugar, torna-lo diferenciado através de características específicas, sejam formas, cores e usos. (Chou; Andrade, 1996).

\subsection{Características do Problema}

A relação entre os diferentes tipos de mobiliários urbanos presentes nos espaços abertos pode ser considerada fator que interfere na imagem que as pessoas têm de suas cidades, contribuindo para tornar o ambiente agradável ou desagradável aos seus usuários. Isto é comprovado por Kilicaslan (2008), ao perceber em seu estudo que os elementos urbanos podem influenciar significativamente a preferência dos indivíduos por determinadas ruas, em relação a aspectos físicos, visuais e de uso.

A necessidade de estudar o mobiliário urbano como um fator que interfere na qualidade visual da paisagem é ressaltada por Guedes (2005). Diversos fatores devem ser levados em consideração quando o objetivo é intervir no espaço urbano através do mobiliário urbano (Quadro 1); haja visto que "muitas vezes, o mobiliário urbano é implantado sem considerar as características das edificações, gerando incompatibilidades formais, e sem considerar a funcionalidade dos espaços, prejudicando o uso", (LONDON, 2000). O que ocorre geralmente nas cidades brasileiras, como diz Ibam (1996), quando a implantação do mobiliário urbano é realizada por diferentes responsáveis, preocupados com o cumprimento de seu próprio serviço, independentemente de outros aspectos importantes. 
Quadro 1 - Orientações para intervenção urbana através de mobiliários urbanos.

\begin{tabular}{|l|l|}
\hline ORIENTAÇÃO & AUTOR \\
\hline Os espaços públicos e seus mobiliários urbanos devem agradar a maioria dos usuários. & Löbach (2001) \\
\hline $\begin{array}{l}\text { O usuário pode ter mais interesse no produto de uso público coletivo quando possui } \\
\text { sentimento de posse. }\end{array}$ & $\begin{array}{l}\text { Burmeister } \\
\text { (2014) }\end{array}$ \\
\hline $\begin{array}{l}\text { A tríade da funcionabilidade do produto e espaço urbano, a racionalidade da sua } \\
\text { construção e forma, e a emotividade devem ser observados no desenvolvimento do } \\
\text { mobiliário urbano e seu contexto de uso. }\end{array}$ & Creus (2002) \\
\hline $\begin{array}{l}\text { O desenho do mobiliário urbano deve atender questões funcionais, aspectos } \\
\text { simbólicos, históricos e culturais do ambiente. }\end{array}$ & $\begin{array}{l}\text { Motenegro } \\
\text { (2005) }\end{array}$ \\
\hline $\begin{array}{l}\text { A linguagem formal adotada pelos elementos contemporâneos deve respeitar as } \\
\text { características das fachadas, dos elementos preservados e da ambiência tradicional do } \\
\text { espaço urbano. }\end{array}$ & Freitas (2008) \\
\hline $\begin{array}{l}\text { O mobiliário urbanodeve ser coerente com as características de cada espaço da } \\
\text { cidade. }\end{array}$ & John e Reis \\
\hline $\begin{array}{l}\text { Formas curvas evocam sentimentos de alegria, harmonia, bem-estar, aconchego e } \\
\text { também proteção. }\end{array}$ & $\begin{array}{l}\text { Papanek } \\
\text { (1995) }\end{array}$ \\
\hline
\end{tabular}

Fonte: Elaborado pelo autor, com base na pesquisa realizada.

\section{MANAUS E NECESSIDADE DE INTERVENÇÃO}

Evidente que Manaus sofreu um grande processo de imposição cultural durante a sua colonização. Entretanto, mesmo com todo o processo de imposição cultural por parte do colonizador europeu, Maciel e Filippini (2010) afirmam que ainda que tenha ocorrido o abafamento da cultura indígena no decorrer da história da cidade de Manaus, a cultura originária ainda se apresenta de forma bastante enraizada. No entanto alertam que a cultura de um lugar só pode se manter viva se a população local a tomar como referência, buscar a afirmação e o sentimento de pertencimento a esses aspectos culturais.

Em seu estudo, Correa e Naoumova (2015) apresentam um tipo de solução. As autoras afirmam que a instalação artística pode ser o diferencial no processo de desenvolvimento do espaço público ou na restruturação do ambiente urbano. Entende-se instalação artística, como um objeto ou conjunto de valores artísticos, formais ou racionais, que transformam espaços em que estão inseridas.

Considerando-se o exposto, verifica-se que o conceito de Placemaking, para transformação de um espaço, baseado em sua cultura, une pessoas muda perspectivas sobre o espaço e transforma a sociedade de forma positiva, sinaliza alternativa para o emprego da proposta deste projeto. Consoante, Fischer (1979) garante que a arte é necessária para que as pessoas se tornem capazes de conhecer e mudar o mundo em que vivem. Logo, a intervenção sugere além da expansão das possibilidades de criação dos artistas a possibilidade de transformar a percepção das pessoas sobre os lugares. (FISCHER, 1979).

Mediante as inúmeras imposições culturais ocorridas na região de Manaus apontadas por Correa e Naoumova (2015), e principalmente das vantagens sobre Intervenções Artísticas e Urbanas destacadas pelos autores, encontrar dentro de um processo metodológico para "não enterrar o passado indígena e nem o europeu, pois, ambos construíram a história da cidade" (MACIEL e FILIPPINI, 2010); é e deve ser de grande importância para o desenvolvimento social e urbano de Manaus, 
principalmente para que "a memória histórica permaneça sempre viva, sendo repassada e geração a geração, e fortalecendo assim, a identidade da cultura da população local", (MACIEL e FILIPPINI, 2010).

\section{MÉTODO DE PESQUISA}

No que se diz respeito a métodos e procedimentos do projeto, Baxter (2011) apresenta um esquema para desenvolvimento de produto relativamente simples, classificadas em quatro etapas, sendo elas: Ideias Preliminares, Especificações, Configurações e Produção. Löbach (2001), apresenta um processo de design focando no processo criativo, similar ao de Baxter, mas com foco para as análises preliminares.

Para a pesquisa, foi estabelecida uma adaptação dos métodos citados, que convergiu em processos complementares. Portanto, foi produzida a introdução do problema, e gerou-se pressupostos baseados no estado da arte. Sem aprofundar em questões específicas as suposições da pesquisa foram baseadas em apontamentos, por meio de observação, das atividades e interações de pessoas comuns.

Para se aprofundar na pesquisa, a coleta de informações foi balizada em três perguntas chaves:

- Qual o nível e o tipo de relação entre os habitantes e a cidade?

- O que é cultura e como ela interfere na relação homem e espaço urbano?

- Como contribuir para a relação entre os habitantes e a cidade (de um ponto de vista antropológico) através do projeto em design?

Com estas perguntas, pretendia-se alcançar respostas sobre como o manauara se comporta em Manaus; o que é definido por outros especialistas como o conceito de cultura e suas consequências no cotidiano atual e também de que forma a cultura, através do design, poderia ser evidenciada ou explorada no meio urbano.

O referencial teórico da pesquisa auxiliou na elaboração de tais perguntas, baseados nos fundamentos de metodologia científica de Marconi e Lakatos (2003). Realizou-se observações sistemáticas, não participante individual, na vida real, onde se observa o cotidiano dos habitantes da cidade em lugares específicos. A escolha dos locais deu-se por pertencer a um circuito turístico e por concentrar atividades culturais e de lazer. O objetivo era observar, como os indivíduos se comportavam nestes lugares, já propícios à interação entre habitante e cidade.

A pesquisa documental foi diretamente em artigos, dissertações, livros, publicações jornalísticas e periódicos. Após os dados coletados, realizaram-se fichamentos das fontes consultadas e logo em seguida a análise das informações coletadas, onde validou-se o que estava sendo observado e apontaram-se possibilidades e ressalvas sobre o assunto da pesquisa geral. Buscou-se sintetizar o texto restante para que ele pudesse conversar em três pontos principais: i) Conceito de Cultura; ii) A importância da Cultura para a Sociedade; e iii) a relação entre Cultura e Cidade. Feito isso, buscou-se definir o problema através dos pontos estudados e apresentados através do estabelecimento dos objetivos do projeto.

A partir dos pontos estudados, percebeu-se que cada etapa se complementava. Não foram realizadas cronologicamente, e sim simultaneamente, possibilitando responder questionamentos de forma cíclica e dinâmica. No fim, foi possível 
estabelecer um método de pesquisa adaptado (Figura 1), que dá margem para a possibilidade de buscar uma solução projetual para o problema, sem que durante uma eventual geração de alternativas, haja a necessidade de voltar a pesquisar sobre algum assunto específico e sim, apenas observar os pontos já levantados anteriormente.

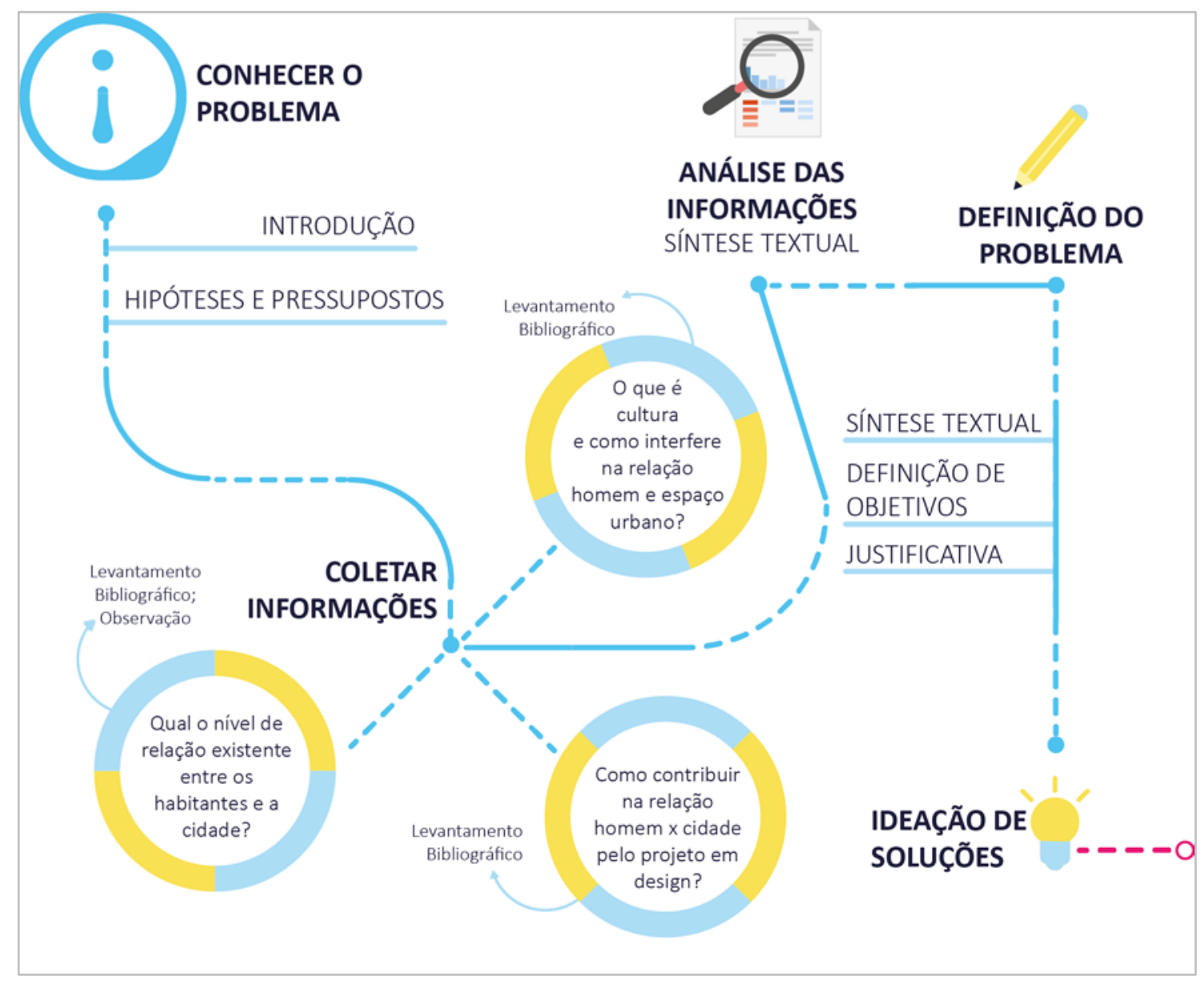

Figura 1 - Método de Pesquisa Adaptado.

Fonte: Elaborado pelo autor, com base na pesquisa realizada.

\section{RESULTADOS}

O conceito de cultura está intimamente com as vivências do homem moderno. Entender a cultura, sua importância e seus reflexos na sociedade é primordial para qualquer pesquisa ou projeto que visa intervir na sociedade baseado na sua cultura. Isto porque, ao entender os aspectos culturais passados e atuais da sociedade em questão, o projeto se apresenta de forma mais concisa e direta, e acima de tudo, correta.

As relações culturais entre homem e cidade podem ser defendidas com base nos seus costumes e fatos históricos; afinal sabe-se que uma a sociedade atual é resultado das ações passadas, e também que suas ações deste presente resultarão em mais tipos de atitudes no futuro. Também é percebido que a cidade, atua como uma manifestação física da sociedade, ao refletir seu modo de viver, de se relacionar.

Por manifestar os costumes de um povo, a cidade torna-se, de certa forma, um organismo vivo, uma extensão dos habitantes de uma localidade. Assim, os 
mobiliários urbanos, além de atender a requisitos formais e estéticos, devem acima de tudo, representar uma sociedade e ir além: possibilitar que os indivíduos de um determinado local se sintam conectados através dos elementos urbanos presentes no seu habitat.

\section{CONCLUSÃO}

Pode-se perceber uma linha de pensamento similar entre historiadores, antropólogos e demais estudiosos, que nos apresentam a cultura como o comum de povos e sociedades, sendo transmitido e adquirido dentro dela e para elas.

Pode-se perceber também que as imposições culturais resultam em características que perduram por anos num povo. Logo, entende-se a importância do relativismo cultural servindo não apenas para trabalhar o respeito entre povos e culturas, mas também para mantê-las vivas e exaltadas.

Percebemos até aqui a importância e os reflexos da cultura, inclusive na formação e construção de espaços urbanos. Pois estes, com todos seus elementos, comunicam e fazem parte da manifestação física da cultura de um povo e de uma região.

Outro fator importante apresentado é levar em consideração todo o processo de criação dos conceitos de mobiliários urbanos para um determinado local. Pois estes, tem peso formal e social dentro do ambiente urbano, e por isso devem atender a maior parte dos requisitos envolvidos no assunto: forma e função.

É preciso entender também não só os pontos entre Manaus versus Habitantes, mas também entender conceitos básicos do design de mobiliários urbanos, do placemaking, de intervenção urbana, para que juntos, todos possam colaborar em informação e na configuração do produto, resultando num projeto que não só interfira no Espaço Público de Manaus, mas que de fato resgate as relações e interações culturais.

Com isso, deseja-se deixar explícito que, o projeto de mobiliário urbano, seja ele qual for, pode e deve ser levado além de uma simples percepção do ambienteÉ necessário cada vez mais que esses projetos incluam aspectos culturais daquele local. Afinal, a comunidade pode sim fazer o espaço urbano vivo, mas é dever dos projetistas criar possibilidades para que as pessoas o faça.

\section{REFERÊNCIAS}

ÁGUAS, Sofia. Do Design ao co-design, uma oportunidade de design participativo na transformação do espaço público. On The Waterfront, 2012.

BASSO, L.; VAN DER LINDEN, C. D. S. Mobiliário Urbano: Origem , Forma e Função. Anais P\&D Design 2010, São Paulo, 2010.

BATISTA, J. A. Reflexões Sobre O Conceito Antropológico De Cultura. Revista Saber Eletrônico, Jussara, 2010. 102-109.

CANEDO, D. “Cultura é o quê?" - Reflexões sobre o conceito de cultura e a atuação dos poderes públicos. V ENECULT - Encontro de Estudos Multidisciplinares em Cultura, Salvador, 2009. 1-14.

CHOAY, F. A alegoria do patrimônio, São Paulo, Ed. Unesp, 2001. 
CHOU, José Walter Teles; ANDRADE, josé roberto de lima. Intervenção urbana e Patrimônio cultural. Observatório de Turismo do Paraná, Curitiba, 2005.

CORREA, C.; NAOUMOVA, N. Novas estratégias de intervenção nos espaços públicos urbanos: a geração de oportunidades através da intervenção de instalações artísticas na cidade. 10 Congresso Internacional Espaços Públicos, Pelotas, 2015. 1-10.

CRAWFORD, M. Everyday urbanism. Nova lorque: The Monacelli Press, 1999.

CREUS, M. Q. Espacios, Muebles y Elementos Urbanos. In: SERRA, J. M. Elementos Urbanos - Mobiliário y Microarquitetura. Barcelona: Gustavo Gili, 1996.

CUCHE, D. O conceito de Cultura nas Ciências Sociais. 2a . ed. Bauru: Edusc, 2002.

FILHO, Antônio Ferreira Colchete. Conceptual intersections: urban furniture, public art and urban imagery. 11th Conference of the International Planning History Society, Barcelona, 2004.

FISCHER, E. A necessidade da arte. Rio de Janeiro: Zahar Editores, 1979.

FREITAS, R. Mobiliário urbano. In: Mascaro. J. (Org), Infraestrutura da Paisagem. Porto Alegre: MaisQuatro, 2008.

GONZÁLEZ-VARAS, I. Conservación de bienes culturales. Madrid, Cátedra, 2003, p. 3738.

GUEDES, João Batista. Design no Urbano: Metodologia de Análise Visual de Equipamentos no Meio Urbano. Tese (Doutorado em Desenvolvimento Urbano, Universidade Federal de Pernambuco, 2005).

IBAM, Instituto Brasileiro de Administração Municipal. Centro de Estudos e Pesquisas Urbanas. Manual de Implantação do Mobiliário Urbano na Cidade do Rio de Janeiro. Rio de Janeiro, 1996.

JACOBS, J. Morte e Vida das Grandes Cidades. São Paulo: WMF MARTINS FONTES, 2014.

KAPLAN, S.; KAPLAN, R. Cognition and Environment: Functioning in an Uncertain World. [S.I.]: Ulrichs Books, 1983.

KILICASLAN, Cisgdem; MALKOC, Emine; TUREL, Hamine. Comparative Analysis of Traditional, Modern, and Renovated Streets in Physical, Visual, and Life Aspects; A Case Study on Buca District Izmir (Turkey). In: Indoor and Built Environment, no 17, p. 403-413, 2008.

KOHLSDORF, Maria Elaine. A apreensão da Forma da Cidade. Brasília: Editora Universidade de Brasília, 1996.

LABURTHE, P.; WARNIER, J.-P. Etnologia-Antropologia. 3a. ed. Petrópolis: Vozes, 2003.

LAMAS, J. M. R. G. Morfologia Urbana e Desenho da Cidade. Lisboa: Fundação Calouste Gulberkian, 2000.

LANG, J. Symbolic aesthetics in architecture: toward a research agenda. In: LANG, J. Environmental Aesthetics, Theory, Research and Applications. [S.I.]: Cambridge University Press, 1992. 
LARAIA, R. D. B. Cultura - Um conceito Antropológico. 23a. ed. Rio de Janeiro: Zahar, 2009.

LONDON, Government Office for. Streets for All: a Guide to the Management of London's Streets. London: English Heritage, 2000.

MACIEL, R. M.; FILIPPINI, E. MANAUS: uma reflexão acerca de seu passado. Revista Eletrônica Aboré - Publicação da Escola Superior de Artes e Turismo Manaus, Manaus, 2010. 37-47.

MARCONI, M. D. A.; LAKATOS, E. M. Fundamentos de metodologia científica. 5ạ. ed. São Paulo: Atlas, 2003.

MARCONI, M. D. A.; PRESOTTO, Z. M. N. Antropologia - Uma introdução. 6ạ. ed. São Paulo: Atlas, 2006.

MASSENZIO, M. A história das religiões na cultura moderna. São Paulo: Hedra, 2005.

MONTENEGRO, G. A produção do mobiliário urbano em espaços públicos: o desenho do mobiliário urbano nos projetos de reordenamento das orlas do RN, Natal, 2005.

MOURA, A. B. D. Turismo em novas perspectivas: identidade cultural manauara sob a ótica do legado indígena. Manaus. 2009.

PEIXOTO, N. B. Paisagens Urbanas. São Paulo: Senac, 1996.

PIZZATO, Gabriela Zubaran; GUIMARÃES, Lua Buarque de Macedo; TONETTO, Leandro Miletto. Bases Para o Desenvolvimento de Diretrizes Projetuais Para o Design. 11 o Congresso Brasileiro de Pesquisa e Desenvolvimento em Design, Gramado, 2014.

PORTAS, N. L'emergenza del progetto urbano. In: Urbanistica 110, Roma, giugno 1998. RAPOPORT, A. Aspectos Humanos de la Forma Urbana. Barcelona: [s.n.], 1978.

STAMPS, A. E. Are environmental aesthetics worth studying? Journal of Architectural and Planning Research, 1989.

UNITED NATIONS UN. Urban Agglomerations. Department of Economic and Social Affairs. Population Division, 2007.

WILLIAMS, R. Palavras-Chaves: um vocabulário de cultura e sociedade. São Paulo: Boitempo, 2007.

ZANIRATO, Silvia Helena. Patrimônio Para Todos: Promoção e Difusão do Uso Público do Patrimônio Cultural na Cidade Histórica, São Paulo, 2006. 